\title{
PRURITOCEPTIVE AND PSYCHOGENIC PRURITUS IN LICHEN SIMPLEX CHRONICUS
}

\author{
Filka Georgieva \\ Department of Dermatology and Venerology, Medical University of Varna
}

\begin{abstract}
Pruritus is a diagnostic hallmark for Lichen Simplex Chronicus (LSC). It elicits a scratch response, initiating the itch-scratch cycle, which in turn aggravates the inflammatory response and exacerbates the disease severity. Treating this symptom can be challenging The purpose of this study is to distinguish which type of pruritus has a leading role in the pathogenesis of LSC by studying changes skin barrier functions and evaluating patients psychopathology. We compare the results from the tests of skin barrier and evaluation of psychiatric scales HAD-A and HAD-D observing 56 adults with diagnosis LSC.
\end{abstract}

Keywords: lichen simplex chronicus, skin barrier evaluation, anxiety

\section{INTRODUCTION}

Lichen Simplex Chronicus (LSC) is a common skin disorder characterized by lichenification of skin as a result of excessive scratching (1). The dominant symptom of dermatosis is pruritus. (2) The pathogenesis of this skin disease is not well distinguished. Disorders of skin barrier are described as a trigger or enhancer of the pathological symptoms of LSC (3). There is an altered skin barrier with varying combination of allergens, irritants and skin pathogens which result in a changed immunoregulatory process. (4) On the other hand psychological factors have an important role in the pathogenesis of LSC. Recent evidence has indicated that psychological stress is associated with exacerbation of different skin condi-

Address for correspondence:
Filka Georgieva
Medical University of Varna
Department of Dermatology and Venerology
55 Marin Drinov St
9002 Varna, Bulgaria
e-mail: filka@abv.bg

Received: March 18, 2016

Accepted: June 3, 2016 tions, including LSC (5). The itch has been classified into four different clinical categories. These include neurogenic, psychogenic, neuropathic, and pruritoceptive (6). These categories were developed based on anatomical, pathophysiological and psychological factors. The itch can be triggered by emotional stress or other underling pruritogenic stimuli. Some authors considered LSC to be a psychosomatic illness (7). This study explores the possible correlation or predomination of pathogenic factors and underlying the type of pruritus in LSC patients

\section{MATERIALS AND METHODS \\ Settings and sample}

The study was conducted among 56 non-hospitalized patients 35 females (62.5\%) and 21 males (37.5\%); the mean age 49.46 years; (range 29-64 years) who visited the dermatology unit in the St. Anna Medical Center between January 2013 and January 2015. The patients have the following inclusion criteria: one or more lichen plaques, highly pruritic, accumulation of normal skin lines, excoriations.

\section{Measures}

We used instrumental methods, including, measuring hydration $(\mathrm{H})$ and transepidermal water 
loss (TEWL) in healthy and damaged skin to evaluate the functioning of stratum corneum (SC) The 14item Hospital Anxiety and Depression scale HAD$A$ and HAD-D was used to measure the levels of anxiety and depression. Personality questionnaires were given to patients during consultation and instruc-
24 months-mean 27g.m2.h (range 20g.m2.h - 32g. $\mathrm{m} 2$.h). The results obtained from measuring $\mathrm{H}$ show similar correlations. The pathological changes were more visible in patients with a duration of LSH of 1924 months - mean 23.15 and more than 24 months, mean $18.75(\mathrm{p}=0.008)$ (Table 1$)$.

Table 1. Distribution according to duration

\begin{tabular}{|c|c|c|c|c|c|c|}
\hline $\begin{array}{l}\text { Distribution of patients } \\
\text { (N\%) according to the } \\
\text { duration of the disease } \\
\text { (months) }\end{array}$ & $\begin{array}{l}\text { TEWL healthy } \\
\text { skin } \\
\text { g.m } 2 . h\end{array}$ & $\begin{array}{l}\text { TEWL dam- } \\
\text { aged skin } \\
\text { g.m2.h }\end{array}$ & $\mathrm{P}$ & $\mathrm{H}$ healthy skin & $\begin{array}{l}\text { H damaged } \\
\text { skin }\end{array}$ & $\mathrm{P}$ \\
\hline $4-6 \mathrm{~N}=16.66 \%$ & 5-15 (10.57) & $15-20(16.42)$ & \multirow{5}{*}{0.048} & $20-40(34.25)$ & $18-35(28.12)$ & \multirow{5}{*}{0.008} \\
\hline $7-12 \mathrm{~N}=19.04 \%$ & $10-17(13)$ & $18-23(20.75)$ & & $26-45(34.4)$ & $18-35(27.1)$ & \\
\hline $13-18 \mathrm{~N}=21.42 \%$ & $5-18(12.71)$ & $10-28(22.85)$ & & $32-40(37.71)$ & $15-33(25.28)$ & \\
\hline $19-24 \mathrm{~N}=30.95 \%$ & $8-24(15.23)$ & $12-38(27.30)$ & & $22-40(32.15)$ & $10-31(23.15)$ & \\
\hline More than $24 \mathrm{~N}=11.90 \%$ & $15-21(17.8)$ & $20-32(27)$ & & $20-40(28)$ & $15-22(18.75)$ & \\
\hline
\end{tabular}

tions on how to fill them in. The patients were asked to fill-in the questionnaires at home. Completed questionnaires were returned at the next visit.

The statistical analysis was performed with SPSS v.21.0 for Windows. Hypotheses were tested using $\chi^{2}$-criteria (for the descriptive profile data). Construct validity was tested by factor analysis. Results with $\mathrm{p}<0.001$ were interpreted as statistically significant.
The most distinct trend for correlation was determined comparing TEWL and $\mathrm{H}$ in pathological skin and severity of the disease. In a group of patients stage II TEWL had a mean value of $31.22 \mathrm{~g} . \mathrm{m} 2 . \mathrm{h}$, while in a group stage I TEWL had a mean value of 16.23g.m2.h. $(p=0.009)$. In a group of patients stage III $\mathrm{H}$ had a s mean value of 20.25 , while in a group stage I $\mathrm{H}$ had a mean value of $28.46(\mathrm{p}<0.003)$ (Table 2).

Table 2. Distribution according to the severity of the disease

\begin{tabular}{l|ccc|ccc}
$\begin{array}{l}\text { Distribution of patients } \\
\text { (N\%) according to the } \\
\text { stage of the disease }\end{array}$ & $\begin{array}{c}\text { TEWL healthy } \\
\text { skin } \\
\text { g.m2.h }\end{array}$ & $\begin{array}{c}\text { TEWL dam- } \\
\text { aged skin } \\
\text { g.m2.h }\end{array}$ & p & H healthy skin & H damaged skin & p \\
Stage I N=30.95\% & $5-18(9.76)$ & $10-23(16.23)$ & & $37.38(26-45)$ & $28.46(15-35)$ & \\
Stage II N=40.47\% & $10-17(14.9)$ & $18-32(24.1)$ & 0.009 & $33.17(20-45)$ & $25.88(15-31)$ & 0.003 \\
Stage III N=28.57\% & $12-24(16.66)$ & $22-38(31.22)$ & & $30.16(22-40)$ & $20.25(10-30)$ & \\
\hline
\end{tabular}

\section{RESULTS AND DISCUSSION}

We compared the TEWL dividing patients according to the duration of the disease. The pathological changes were more visible in patients with duration of LSC of 19-24 months - mean $27.30 \mathrm{~g}$. $\mathrm{m} 2 . \mathrm{h}$ (range 12g.m2.h - 38g.m2.h) and more than
Bouwstra and associates (2006) reported a correlation between the clinical characteristics of skin diseases and the changes in the barrier function (8). Other authors found no statistically significant relationship between the disturbed homeostasis of the skin barrier and the expression of the disease symptoms (9). The results from our study show the pres- 
ence of such dependence in dividing patients by disease severity (Table 3). tween $0-7 ; 17.98 \%$ have mild anxiety- range $8-10$; $3.68 \%$ have moderate anxiety range 11-14 and just

Table 3. The correlation between levels of disturbance in the skin barrier and severity of LSC

\begin{tabular}{lc|c|c|c|c|}
\hline \multirow{2}{*}{ TEWL and H } & & \multicolumn{4}{|c|}{ Stage of LSC } \\
\cline { 2 - 6 } & Stage I & Stage II & Stage III & Stage IV & $\mathrm{p}$ \\
\hline Normal & $0 \%$ & $0 \%$ & $0 \%$ & $0 \%$ & \\
Mild changes & $59.3 \%$ & $37.0 \%$ & $3.7 \%$ & $0 \%$ & $<0.001$ \\
Moderate changes & $45.5 \%$ & $54.5 \%$ & $64.7 \%$ & $0 \%$ & \\
Severe changes & $0 \%$ & $35.3 \%$ & $21.8 \%$ & $0 \%$ & \\
\hline \hline
\end{tabular}

In 1985 Werner and associates published data about increased TEWL in healthy and pathological skin in a study of patients with atopic dermatitis. As a result, the authors presume primary defect in the epidermal barrier (10). Our results showed that from all patients included in the study only $30.95 \%$ had pathology in the skin barrier (increased TEWL and decreased $\mathrm{H}$ ) when measuring a healthy skin stretch. Disturbed pathological function of skin barrier (increased TEWL and reduced $\mathrm{H}$ ) when measuring o damaged skin was reported in $85.71 \%$. These results questioned the existence of a primary defect in the epidermal barrier and its leading role in unlocking LSC. The correlation between the degree of damage of the skin barrier and the severity of the disease give a reason to assume that the itch aggravates the disease and leads to a dysfunction of the barrier homeostasis.

Results from the 14item Hospital Anxiety and Depression scale HAD-A and HAD-D show that in $77.29 \%$ of patients the rate of anxiety is normal be-

\section{anxiety}

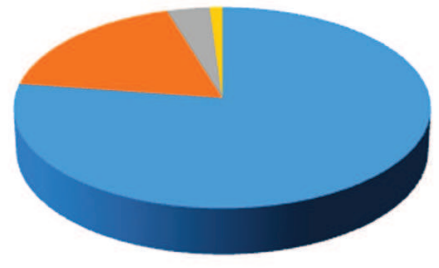

normal level

mild

moderate

severe
$1.05 \%$ have severe anxiety range 15-21 (Figure 1). The data from the depression evaluation show that most of the patients $94.73 \%$ do not have depression range $0-7 ; 4.21 \%$ have mild depression and $1.05 \%$ have moderate depression (Figure 2).

\section{depression}

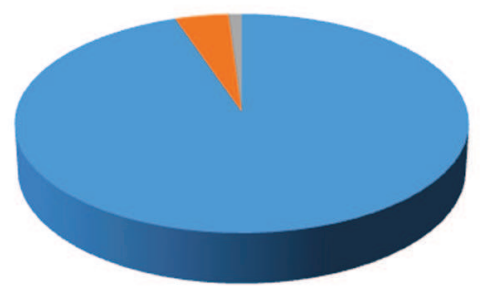

no

mild

moderate

severe

Fig. 2. Depression distribution

With regard to the duration of the disease the range was from $57.14 \%$ (6 to 8 months) to $87.75 \%$ (1824 months). Mild anxiety was marked the most significant in patients with disease duration of 24-30 months-33.34\%, and at least $4.28 \%$ in LSC with duration from 6 to 8 months. Moderate anxiety was most significant in the group of patients with duration 6-8 months $-28.57 \%$. Regarding the severity of disease results show no correlation between the levels of anxiety and the severity of LSC. The patients with severe anxiety were in a group of stage II of the disease and patients in a group of stage III show normal levels of anxiety. So the results obtained from the comparison the level of anxiety and disease characteristics show 
little correlation with the duration and absence of correlation with the severity of LSC (Table 4).
Interesting results were obtained when comparing the anxiety level and evaluating the functioning

Table 4. Distribution of anxiety according severity of LSC

\begin{tabular}{l|c|c|c|c|c|}
\multirow{2}{*}{\multicolumn{1}{c|}{ Anxiety }} & \multicolumn{5}{c|}{ Stage of the disease } \\
\cline { 2 - 6 } & Stage I & Stage II & Stage III & Stage IV & $\mathrm{p}$ - \\
normal & $12(33.3 \%)$ & $18(50 \%)$ & $6(16.7 \%)$ & $0(0 \%)$ & \\
mild & $7(53.8 \%)$ & $3(23 \%)$ & $3(23.1 \%)$ & $0(0 \%)$ & 0.092 \\
moderate & $2(50.0 \%)$ & $1(25 \%)$ & $1(25.0 \%)$ & $0(0 \%)$ & \\
severe & $0(0 \%)$ & $0(0 \%)$ & $2(100 \%)$ & $0(0 \%)$ & \\
\hline \hline
\end{tabular}

LSC is a skin disease included in a group of medical conditions due to psychological factors $(11,12)$. Simonetta and associates (2015) published data reaffirming that psychogenic factors play an important role in the development of LSC (13). Liao and associates (2014) in their retrospective study found that patients with marked anxiety are at 1:41 higher risk of developing LSC compared to the healthy population (14). In our study the results from comparing the level of anxiety with the duration of LSC support the theory of the psychogenic origin of itch in the pathogenesis of the disease (15). The lack of correlation between the severity of LSC and the levels of anxiety support the data export by Perez et al (2009) that in some patients the psychogenic factor is a leading cause of the disease (16).

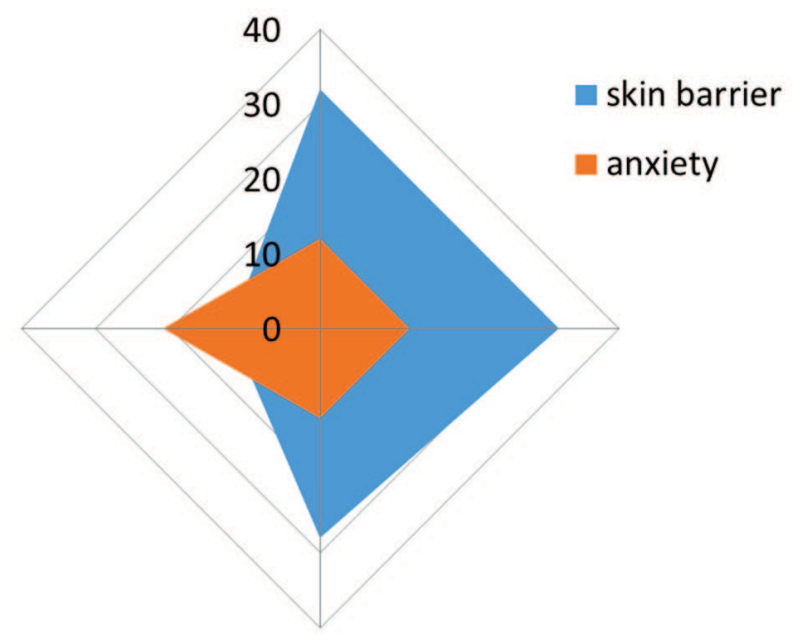

Figure 3. The correlation between the functioning of the skin barrier and the anxiety levels of the skin barrier. Results show that patients with mild and moderate anxiety have light changes in the functioning of the skin barrier (19.64\%). The patients with the lowest $\mathrm{H}$ and the highest TEWL have normal results from the HAD-A and HAD-D scales $(21.13 \%)(\mathrm{p}=0.001)$ (Figure 3$)$.

\section{CONCLUSION}

Disorders of the skin barrier are described as a trigger of pruritoceptive pruritus while psychosomatic disorders are associated with psychogenic pruritus in patients with LSC. The absence of correlation between changes in $\mathrm{H}$ and TEWL and psychosomatics means that in patients suffering from LSC there are two independent pathological ways of development of the illness.

\section{REFERENCES}

1. Torello Lotti GB. Francesca Prignano. Prurigo nodularis and lichen simplex chronicus. Dermatologic Therapy 2008; 21:42-46

2. Martin-Braufau R, Corbalan-Berna J, RamirezAndrero A. Braufau-Redondo C. LimlnanaGras R. Personality differences between patients with lichen simplex chronicus and normal population:A study of pruritus. Eur.J.Dermatol 2010; 20(3):359-363

3. Yosipovitch G, Samuel LS. Neuropathic and psychogenic itch. Dermatol Ther. 2008; 21(1):32-41.

4. Proksch E, Fölster-Holst R, Jensen JM Skin barrier function, epidermal proliferation and differentiation in eczema Journal of dermatological science, 2006; 43(3):159-169

5. Kini SP, DeLong LK, Veledar E, McKenzie-Brown AM, Schaufele M, Chen SC. The impact of pruritus 
on quality of life: the skin equivalent of pain. Arch Dermatol. 2011; 147(10):1153-1156

6. Lilit Garibyan, Curtis G. Rheingold, Ethan A. Lerner Understanding the pathophysiology of itch Dermatol Ther2005; 23(4):591-599

7. WillemsenR, Raseeuuw D, VanderlindenJ.Alexithymia and dermatology: the scale of the art Int J Dermatol 2008; 47; 903-910

8. Bouwstra JA, PonecM.The skin barrier in healthy and disease state. Biochim Biophys Acta.2006; 1758(12):2080-2095

9. Grubauer G, Elias PM, Feingold KR. Transepidermal water loss; the signal for recovery of barrier structure and function \, J Lipid Res 1989; 30; 323-333

10. Werner $Y$, Lindberg M. Transepidermal water loss in dry and clinically normal skin in patients with atopic dermatit. Acta Derm Venereol 1985; 65; 102-105

11. Thaipisuttikul Y. Pruritic skin diseases in the elderly. J Dermatol. 1998. 25(3):153-157.

12. Koblenzer CS. Psychosomatic concepts in dermatology Arch Derm, 2003; 119(6); 501-512

13. Simonetta C, Burns EK, Guo MA. Vulvar Dermatoses: A Review and Update. Mo Med. 2015: 112 (4):301-307

14. Picardi, A., Amerio,P., Baliva,G., at al Recognisson of depressive and anxiety disorders in dermatological outpatients. Acta DermVenerol, 2004, 84,213-217

15. TsintsadzeN, Beridze L, TsintsadzeN, at al Psychosomatic aspects in patients with dermatologic disease. Georgian Med News 2015 70-75

16. Perez E, Manuel J, Curto Iglesias JR, Antuna Bernardo S. Gercia VegaE. Gonzalez Menendez A et al Perfil psichologico y calidat de vida pacientes con enfermedades dermatológicas. Psicothema 2009; $12 ; 30-34$ 